\title{
Photolysis of frozen iodate salts as a source of active iodine in the polar environment
}

\author{
Óscar Gálvez ${ }^{1, \mathrm{a}}$, M. Teresa Baeza-Romero ${ }^{2}$, Mikel Sanz ${ }^{2, \mathrm{~b}}$, and Alfonso Saiz-Lopez ${ }^{3}$ \\ ${ }^{1}$ Departamento de Física Molecular, Instituto de Estructura de la Materia, IEM-CSIC, 28006 Madrid, Spain \\ ${ }^{2}$ Escuela de Ingeniería Industrial, Universidad de Castilla-La Mancha, 45071 Toledo, Spain \\ ${ }^{3}$ Department of Atmospheric Chemistry and Climate, Institute of Physical Chemistry Rocasolano, CSIC, \\ 28006 Madrid, Spain \\ anow at: Departamento de Física Interdisciplinar, Facultad de Ciencias, Universidad Nacional de Educación a Distancia, \\ 28040 Madrid, Spain \\ b now at: Institute of Physical Chemistry Rocasolano, CSIC, 28006 Madrid, Spain
}

Correspondence to: Óscar Gálvez (oscar.galvez@csic.es, oscar.galvez@ccia.uned.es)

Received: 15 September 2015 - Published in Atmos. Chem. Phys. Discuss.: 15 October 2015

Revised: 22 September 2016 - Accepted: 26 September 2016 - Published: 12 October 2016

\begin{abstract}
Reactive halogens play a key role in the oxidation capacity of the polar troposphere. However, sources and mechanisms, particularly those involving active iodine, are still poorly understood. In this paper, the photolysis of an atmospherically relevant frozen iodate salt has been experimentally studied using infrared (IR) spectroscopy. The samples were generated at low temperatures in the presence of different amounts of water. The IR spectra have confirmed that, under near-ultraviolet-visible (UV-Vis) radiation, iodate is efficiently photolysed. The integrated IR absorption coefficient of the iodate anion on the band at $750 \mathrm{~cm}^{-1}$ has been measured to be $A=9.8 \pm 0.5 \times 10^{-17} \mathrm{~cm} \mathrm{molecule}^{-1}$. The photolysis rate of the ammonium iodate salt was measured by monitoring the decay of ammonium or iodate IR bands (1430 and $750 \mathrm{~cm}^{-1}$ respectively) in the presence of a solar simulator. The absorption cross section of the liquid solutions of ammonium iodate at wavelengths relevant for the troposphere ( 250 to $400 \mathrm{~nm}$ ) has been obtained and used to estimate the photolytic quantum yield for the frozen salt. Finally, using an atmospheric model, constrained with the experimental data, we suggest that the photolysis of iodate in frozen salt can potentially provide a pathway for the release of active iodine to the polar atmosphere.
\end{abstract}

\section{Introduction}

Atmospheric iodine compounds are present in the marine and polar boundary layers (Saiz-Lopez et al., 2012), where they play a relevant role in catalytic ozone destruction (SaizLopez et al., 2007b; Read et al., 2008), and they could also be involved in new particle formation in the polar environment (Allan et al., 2015; Roscoe et al., 2015). Moreover, in the polar atmosphere, iodine has also been suggested as one of the possible sinks of gaseous elemental mercury (Calvert and Lindberg, 2004; Saiz-Lopez et al., 2008).

Although the concentration of atmospheric iodine is highly variable at different regions, ground- (Frieß et al., 2001; Saiz-Lopez et al., 2007b; Atkinson et al., 2012) and satellite-based instrumentation (Saiz-Lopez et al., 2007a; Schönhardt et al., 2008) measurements have confirmed remarkably high concentrations (up to $20 \mathrm{pptv}$ ) of IO in coastal Antarctica. Nevertheless, the sources and mechanisms of iodine emissions from ice remain poorly understood (SaizLopez et al., 2015; Kim et al., 2016).

Apart from observations of gaseous iodine species, different studies have conducted analysis of the iodine fraction in rainwater (Laniewski et al., 1999) and aerosols (Baker et al., 2000). In all of them, iodine concentrations are considerably enriched over seawater, and an appreciable fraction of soluble iodine species like $\mathrm{I}^{-}$and $\mathrm{IO}_{3}^{-}$is observed, although the mechanism determining the $\mathrm{I}^{-} / \mathrm{IO}_{3}^{-}$ratio is still unclear. 
Thus, for example since $\mathrm{IO}_{3}^{-}$has been considered an inert inorganic iodine species, and therefore a sink molecule in the atmospheric iodine cycle, model calculations (Pechtl et al., 2006) suggest that $\mathrm{IO}_{3}^{-}$should accumulate in marine aerosol. However, several field campaigns (Baker, 2004; Gilfedder et al., 2008) have revealed that the iodide / iodate ratio is rather variable in aerosol, showing significant $\mathrm{I}^{-}$concentration.

A recent study has suggested that $\mathrm{IO}_{3}^{-}$anions show a substantial reactivity in frozen solutions under near-ultravioletvisible (UV-Vis) light irradiation (Spolaor et al., 2013). During the irradiation of $\mathrm{IO}_{3}^{-}$frozen solutions, reactive gaseous iodine species were produced and converted to iodine oxide particles (IOPs) for detection. Inspired by these results, we have further studied the photostability of iodate frozen salts to assess its potential role in iodine emissions to the polar atmosphere. In this work, we have determined the absorption cross section of the $\mathrm{NH}_{4} \mathrm{IO}_{3}$ solution, which has been used to estimate for the first time the absorption cross section and quantum yield of frozen ammonium iodate solutions at wavelengths relevant for the troposphere, from 250 to $400 \mathrm{~nm}$. The product of these two quantities gives us the efficiency of the photolytic process, but these values should be taken as a lower limit that needs to be explored in further detail in future laboratory work. This information has been incorporated into an atmospheric model to assess the potential of iodate photolysis to release reactive iodine to the Antarctic boundary layer during springtime.

\section{Experimental methods}

For the study of the photolysis of iodate salts, we have tested several iodated compounds. Firstly, the photolysis of frozen solutions of $\mathrm{KIO}_{3}$ was studied, and significant photolysis was observed (for more details see the Supplement). However, due to the overlapping of the $\mathrm{IO}_{3}^{-}$IR band with water absorption, we studied $\mathrm{NH}_{4} \mathrm{IO}_{3}$ for the following reasons:

i. As mentioned above, it was not possible to monitor iodate signal in the presence of high concentrations of water since the infrared iodate band overlaps with water absorptions. The fact that the chosen salt has a cation like $\mathrm{NH}_{4}^{+}$that presents a band with no interference (and that it is consumed in a $1: 1$ ratio with iodate; see Supplement) allowed us to measure the photolysis of iodate indirectly as described below.

ii. As far as we know, there is no information in the literature of the integrated value of the IR absorption coefficient of the iodate band, and in consequence it was not possible to directly quantify the amount of iodate in the samples. One of the possibilities to solve this problem is to use an iodate salt for which the integrated absorption coefficient of the IR band of the counter-ion was known, like ammonium iodate. This was the procedure that we have followed, and more details of these calculations are given in the next section.

iii. Moreover, ammonium iodate is expected to be an abundant iodate salt in the atmosphere, since ammonium concentrations are high in some environments, and it could be deposited into the ice as large fluxes of iodinated compounds have been observed during glacial periods (Spolaor et al., 2013); the presence of ammonium ions in ice samples is also expected. Moreover, ammonium and iodinated compounds have been detected at the same time in melting Arctic sea ice, implying that this salt could be atmospherically relevant (Assmy et al., 2013). Note, however, that other salts such as $\mathrm{NaIO}_{3}$ or $\mathrm{KIO}_{3}$ would be representative of polar environments too, and further experiments using these compounds should be addressed in the future.

Solid samples containing iodate anions were produced through the sudden freezing of droplets of aqueous solutions of $\mathrm{NH}_{4} \mathrm{IO}_{3}$ on a cold $\mathrm{Si}$ substrate located inside a vacuum chamber. A detailed description of the experimental setup can be found elsewhere (Maté et al., 2009; Gálvez et al., 2010), and only a brief description of the most relevant aspects for the present experiments is given here. The solid substrate is mounted in a $\mathrm{Cu}$ block in contact with a liquid nitrogen Dewar. The substrate temperature can be controlled with $1 \mathrm{~K}$ accuracy between 90 and $300 \mathrm{~K}$. The vacuum chamber, which is coupled to a Bruker VERTEX 70 Fourier transform infrared spectroscopy (FTIR) spectrometer through a purged pathway, is evacuated with a turbomolecular pump to a background pressure of $\sim 10^{-8}$ mbar. Transmission spectra of the samples were recorded, with $2 \mathrm{~cm}^{-1}$ resolution, using an MCT (mercury cadmium telluride) detector refrigerated with liquid nitrogen. Liquid solution droplets from a room temperature pulsed valve (General Valve, series 9), usually employed for the generation of free jets and molecular beams (Abad et al., 1995), were made to impinge on the cold $\mathrm{Si}$ substrate placed at $\sim 15-20 \mathrm{~mm}$. When a desired amount of sample is on the substrate, this can be rotated to record the IR spectra, or to be processed by simulated solar light. A scheme of the experimental setup is shown in Fig. 1. Solar irradiance was simulated by a $1000 \mathrm{~W}$ LOT ${ }^{\circledR}$ Xenon Arc lamp that radiates between around $250 \mathrm{~nm}$ and $2.5 \mu \mathrm{m}$, although an important fraction of the output is given below $900 \mathrm{~nm}$ according to the supplier of this lamp, where a fairly constant spectral irradiance is obtained between 300 and $900 \mathrm{~nm}$. Power light received on the substrate is measured by a portable thermal detector meter, model 407A by Spectra-Physics, which operates in a wavelength range from $250 \mathrm{~nm}$ to $11 \mu \mathrm{m}$ without significant sensitivity variations (less than $3 \%$ ).

UV-Vis spectra of the studied salts were obtained in water solution at different concentrations using both a UV-Vis Uvikon spectrophotometer 930 from Kontron Instruments and a double-beam spectrophotometer (Shimadzu UV-3600), 


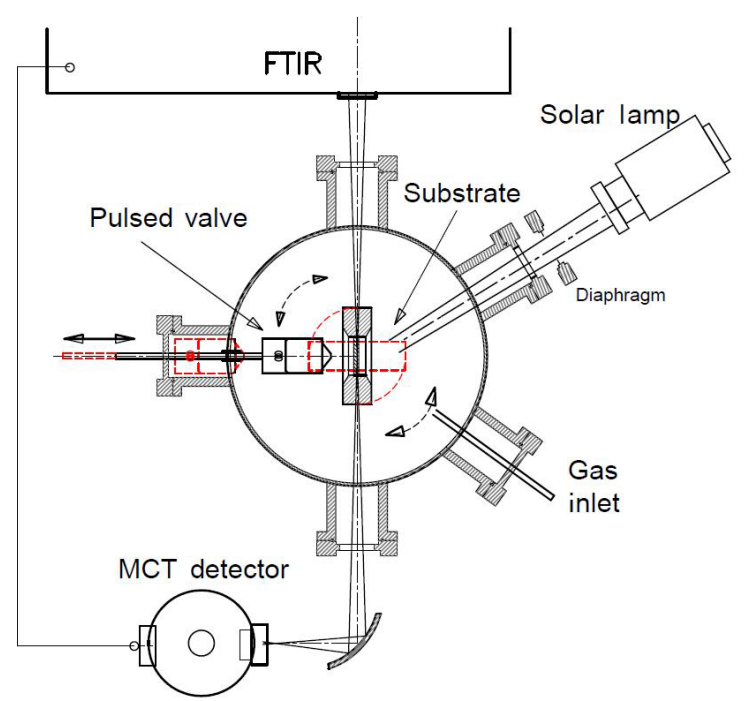

Figure 1. Schematic view of the experimental setup.

equipped with quartz cuvettes of $10 \mathrm{~mm}$ size. The spectra resolution was fixed at $0.5 \mathrm{~nm}$, from 190 to $500 \mathrm{~nm}$.

In all experiments, a pulsed valve was filled with a solution $0.1 \mathrm{M}$ of ammonium iodate (Across Organics, for analysis). A slight He overpressure behind the liquid solution filling the valve improved the performance. This generation procedure does not lead to a uniform film, and the thickness of the ice samples, which typically range from $\sim 0.1$ to $1 \mu \mathrm{m}$ (Maté et al., 2012), can vary among different experiments. Solid samples generated by this technique contain compact ice structures in a hyperquenched glassy water morphology (Mayer, 1985), in which the water molecules retain their amorphous liquid structure and where ions are solvated by water molecules instead of being segregated in the ice (Maté et al., 2012). When the temperature of the substrate is below that of water sublimation (around $170 \mathrm{~K}$ ), the ice mixture concentration is somewhat comparable to the liquid solution $(0.1 \mathrm{M})$, and the infrared spectra of these ices are largely dominated by water absorptions. In these cases, water bands hide the IR features of the salt and prevent monitoring its evolution during irradiation. For this reason, most samples were slowly warmed above water sublimation to achieve a lower water concentration to avoid such interference. Nevertheless, some samples were also reserved in their original diluted salt proportion to explore the effect of this variable. We refer to the samples that have suffered this process as hyperquenched $(H Q)$ samples, as their morphology is provided by the hyperquenching technique. However, in other experiments, samples deposited by hyperquenching are annealed to high temperature (up to $240 \mathrm{~K}$ for around $10 \mathrm{~min}$ ) to dry them completely, and then, once they cool down to a selected low temperature (e.g. 100 or $140 \mathrm{~K}$ ), a controlled water vapour flux is added to be adsorbed onto the dried salt, condensing on the sample. With this procedure, solid sam- ples present a different morphology since water molecules are deposited uniformly on the salt surface, resulting in a more porous structure. In addition, when the condensation of water occurs at $100 \mathrm{~K}$, a homogeneous film of low-density amorphous water ice is deposited on top of the salt, but at deposition temperature of ca. $140 \mathrm{~K}$ or above, the ice film has a crystal cubic ice structure (Maté et al., 2012). When this technique is used and water is added from the vapour phase, we refer to these samples as vapour deposited (Vap) samples.

Initially, deposition at low temperature $(<120 \mathrm{~K})$ leads to amorphous ices samples, which show high specific surface areas (SSAs) (Maté et al., 2012), around 100 times higher, or even more, than typical atmospheric ice samples. However, when temperature is increased at $140 \mathrm{~K}$, amorphous samples are irreversibly transformed to cubic crystal ice, leading to a reduction of the SSA by a factor of 100 or even higher (Ocampo and Klinger, 1982), which are common values of freshly atmospheric ice samples. It is worth noting that amorphous solid water (ASW) has recently been chosen as a model for the disordered interstitial air-ice interface within snowpack (Marcotte et al., 2015).

Due to the requirements of the experimental setup, the ratio of $\mathrm{NH}_{4} \mathrm{IO}_{3}: \mathrm{H}_{2} \mathrm{O}$ in the samples is considerable much higher than for environmental ices; however, some more diluted samples were also studied to assess this effect on the photolysis process.

To summarize the procedure to generate the samples, they were firstly generated by HQ deposition at 100, 140, 160, 200,260 or $298 \mathrm{~K}$, and after deposition at those temperatures, three different processes were carried out: (i) the samples at the deposition temperature were just irradiated; (ii) samples deposited at low temperatures were firstly annealed to around $170 \mathrm{~K}$ for some minutes to eliminate part of the water, then cooled down to a certain low temperature (from 100 to $140 \mathrm{~K}$ ) and then irradiated; (iii) or samples were annealed to $240 \mathrm{~K}$ for around $10 \mathrm{~min}$ to dry them completely, then cooled down at a selected low temperature at which a certain amount of water from vapour phase was deposited and finally irradiated. A complete list of all the samples and deposition conditions (and the resulting rate constants of the photolysis process) is included in Table S1 in the Supplement.

\subsection{Determination of the concentration of the different species in the samples}

Column densities of water, $\mathrm{NH}_{4}^{+}$and $\mathrm{IO}_{3}^{-}$ions in the ice mixtures were calculated via the Lambert-Beer equation, using the integrated values of the infrared absorption bands and the corresponding integrated absorption coefficients, $A$. The bands chosen for this purpose were the $v_{2}$ and $v_{2}+v_{R}$ bands of water around 1650 and $2220 \mathrm{~cm}^{-1}$, respectively; the $v_{4}$ band of $\mathrm{NH}_{4}^{+}$around $1430 \mathrm{~cm}^{-1}$; and the $\nu_{3}$ band of $\mathrm{IO}_{3}^{-}$at ca. $740 \mathrm{~cm}^{-1}$. For water band intensity, we have used the values reported by Mastrapa et al. (2009) for an amorphous or crystalline (cubic) phase at $100 \mathrm{~K}$. For Vap samples at $100 \mathrm{~K}$ 
the values of amorphous ice used are $A\left(\mathrm{H}_{2} \mathrm{O}\right)_{\text {amorphous }}=$ $1.6 \times 10^{-17}$ and $9.8 \times 10^{-18} \mathrm{~cm} \mathrm{molecule}^{-1}$, while for Vap samples at $140 \mathrm{~K}$ or HQ samples (when water was annealed at higher temperatures) the integrated absorption coefficients of cubic ice are more representative: $A\left(\mathrm{H}_{2} \mathrm{O}\right)_{\text {cubic }}=$ $1.8 \times 10^{-17}$ and $1.1 \times 10^{-17} \mathrm{~cm} \mathrm{molecule}^{-1}$, for 1650 and $2220 \mathrm{~cm}^{-1}$ bands. In the case of $\mathrm{NH}_{4}^{+}$, different values of the absorption coefficient have been reported in the literature, ranging from 2.5 to $4.4 \times 10^{-17} \mathrm{~cm}$ molecule ${ }^{-1}$ (Maté et al., 2009; Schutte and Khanna, 2003). Due to these discrepancies, we have selected a suitable value of $4.0 \times$ $10^{-17} \mathrm{~cm}$ molecule ${ }^{-1}$, close to that given by Schutte and Khanna (2003) for solid samples, which are more representative of our case. For iodate, we are not aware of previous data of $A$ values in the IR region, so we have determined the value in this paper. In this case, we have estimated this value for pure ammonium iodate samples, based on that previously given for $\mathrm{NH}_{4}^{+}$, obtaining mean integrated absorption coefficients $A\left(\mathrm{IO}_{3}^{-}\right)=9.8 \pm 0.5 \times 10^{-17} \mathrm{~cm}_{\text {molecule }}{ }^{-1}$ for the band centred at $750 \mathrm{~cm}^{-1}$ (details are shown in the Supplement).

\subsection{Calculation of spectral irradiance received by the samples}

We assumed that the observed photolysis of ammonium iodate samples should be mainly due to the highest frequency photons (below $400 \mathrm{~nm}$ ) emitted by the solar lamp. The reason is that $\mathrm{IO}_{3}^{-}$in aqueous media absorbs light only in the UV range (Awtrey and Connick, 1951), at wavelengths below $270 \mathrm{~nm}$, which is also in agreement with our near UVVis spectra of iodate salts (see Fig. 2). For this reason, it is important to delimit the blue cut-off of the irradiation received by the samples, which is determined by the glass window of the vacuum chamber (see Fig. 1). In consequence, the UV-Vis spectrum of the glass window was recorded to define the transparent interval of frequencies, especially the UV cut-off; see Fig. 2. Taking into account this spectrum, and in combination with that provided by the lamp manufacturer for the spectral irradiance of the lamp at $0.5 \mathrm{~m}$, we can estimate that only $6.3 \%$ of the total lamp power received by the substrate allocated inside the vacuum chamber is due to light of wavelengths below $400 \mathrm{~nm}$ (see the Supplement for more details). Consequently, since our thermopile covers the whole range of frequencies without significant variations, and taking into account that the average reading in the thermopile along the experiments was around $1.5 \mathrm{~W} \mathrm{~cm}^{-2}$ (which was regularly monitored during the experiments), we can estimate that the substrate was irradiated with an average light power of $0.095 \mathrm{~W} \mathrm{~cm}^{-2}$, within the wavelength range of 250 to $400 \mathrm{~nm}$.

In order to illustrate whether this irradiance power is characteristic of environmental conditions, it could be compared with the average irradiance (also below $400 \mathrm{~nm}$ ) received at the Earth's surface, which has been estimated as around

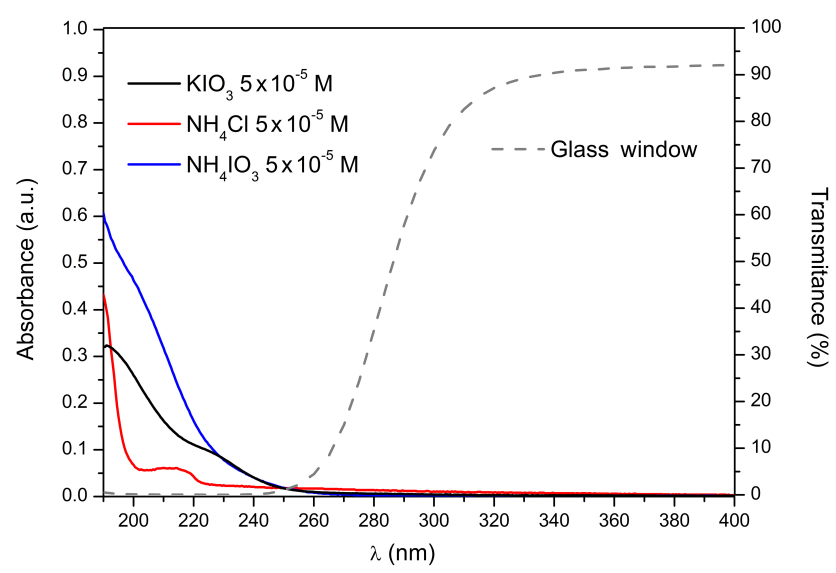

Figure 2. UV-Vis absorption spectra from 190 to $400 \mathrm{~nm}$ for $\mathrm{KIO}_{3}$, $\mathrm{NH}_{4} \mathrm{Cl}$ and $\mathrm{NH}_{4} \mathrm{IO}_{3}$ aqueous solutions (in absorbance unit) and the glass window present during irradiation (in \% transmittance).

$0.01 \mathrm{~W} \mathrm{~cm}^{-2}$ (see the Supplement for more details), which results in around 9-times-lower irradiance than that received by the samples in our experiments. Nevertheless, we should take into account several additional factors. For instance, our silica substrate is highly reflective to visible light; therefore since the irradiation occurs perpendicularly to the substrate (see Fig. 1), probably our samples received double the flux (incident and reflected) of that calculated above. This factor sets our calculated irradiance power as a lower limit. However, note that, due to our experimental procedure, samples are not homogeneously distributed on the substrate, and thus the photon flux impacting on the samples was, to a certain degree, lower. These considerations are further explored in the following section.

Note that, due to the limitations mentioned above and the use of the thermopile for the determination of the photon flux, there are limitations and uncertainties (thermopile is practically insensible to photon frequency), and other methodologies (as for example the use of chemical actiometers) could be more adequate to quantify this parameter.

\section{Results and discussions}

\subsection{Laboratory experiments}

Figure 3 shows IR spectra of different samples of solid ammonium iodate salt (with a small water proportion) at 200 and $100 \mathrm{~K}$ including those of 4 and $2: 1 \mathrm{H}_{2} \mathrm{O} / \mathrm{NH}_{4} \mathrm{IO}_{3}$ ice mixtures deposited at $100 \mathrm{~K}$ obtained by the HQ technique and via $\mathrm{Vap}_{2} \mathrm{O}$, respectively. Table 1 displays the positions of IR bands of $\mathrm{NH}_{4} \mathrm{IO}_{3}$. These IR spectra are shown in Fig. 3 as well. All experiments and conditions are summarized in Table S1 in the Supplement. Sharper and more defined bands of $\mathrm{NH}_{4}^{+}$and $\mathrm{IO}_{3}^{-}$appear in spectra at $100 \mathrm{~K}$, showing also a slight displacement, which are typical effects when tem- 
Table 1. Positions (in $\mathrm{cm}^{-1}$ ) and assignment of the mid-IR spectra bands of the $\mathrm{NH}_{4} \mathrm{IO}_{3} / \mathrm{H}_{2} \mathrm{O}$ ice mixtures shown in Fig. 3 .

\begin{tabular}{lllrl}
\hline Experiment & $v_{1}, v_{3}\left(\mathrm{IO}_{3}^{-}\right)$ & $v_{4}\left(\mathrm{NH}_{4}^{+}\right)$ & $2 v_{1}, v_{3}\left(\mathrm{IO}_{3}^{-}\right) ?$ & $2 v_{4}, v_{2}+v_{4}, v_{3}\left(\mathrm{NH}_{4}^{+}\right)$ \\
\hline $6: 1 \mathrm{NH}_{4} \mathrm{IO}_{3} / \mathrm{H}_{2} \mathrm{O} 200 \mathrm{~K}$ & $742,792^{\mathrm{sh}}$ & $1428,1451^{\mathrm{sh}}$ & 1683 & $2839,3020,3165$ \\
$8: 1 \mathrm{NH}_{4} \mathrm{IO}_{3} / \mathrm{H}_{2} \mathrm{O} 100 \mathrm{~K}$ & $738,772^{\mathrm{sh}}, 792^{\mathrm{sh}}$ & $1432,1456^{\mathrm{sh}}$ & 1683 & $2839,3020,3154$ \\
$4: 1 \mathrm{H}_{2} \mathrm{O} / \mathrm{NH}_{4} \mathrm{IO}_{3} 100 \mathrm{~K} \mathrm{HQ}$ & $745,769^{\mathrm{sh}}, 794^{\mathrm{sh}}$ & $1432,1456^{\mathrm{sh}}$ & 1683 & $2839,3020,3154^{\mathrm{sh}}$ \\
$2: 1 \mathrm{H}_{2} \mathrm{O} / \mathrm{NH}_{4} \mathrm{IO}_{3} 100 \mathrm{~K} \mathrm{Vap}$ & $749,792^{\mathrm{sh}}$ & $1432,1456^{\mathrm{sh}}$ & 1683 & $2839,3020,3154^{\mathrm{sh}}$ \\
\hline
\end{tabular}

sh Shoulder.

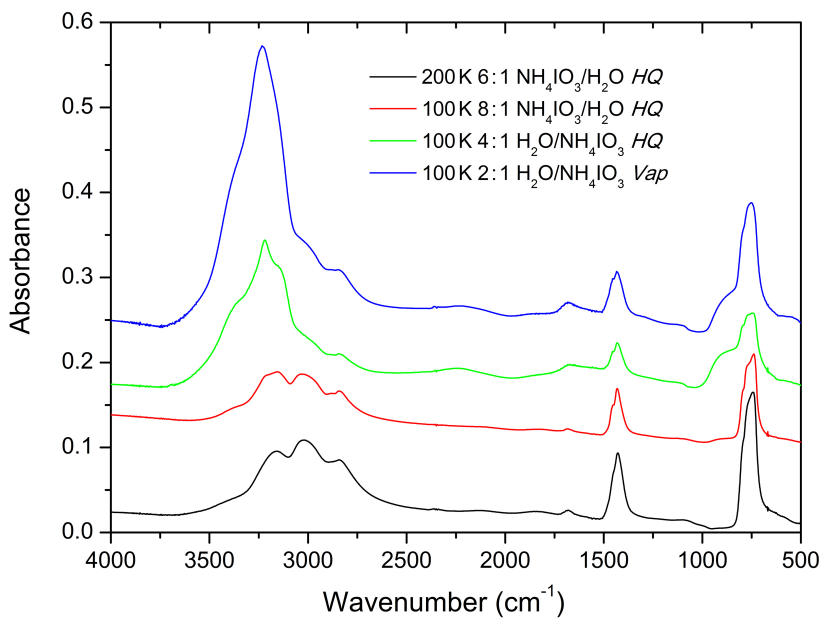

Figure 3. Mid-IR transmission spectra of pure $\mathrm{NH}_{4} \mathrm{IO}_{3}$ and $\mathrm{H}_{2} \mathrm{O} / \mathrm{NH}_{4} \mathrm{IO}_{3}$ ice mixtures generated at different temperatures.

perature is decreased (Gálvez et al., 2009). When water is present, $\mathrm{IO}_{3}^{-}$bands undergo a small blue shift, which can be related to the overlap with the $v_{R}$ libration water mode at ca. $800 \mathrm{~cm}^{-1}$. Moreover, some differences in the water bands become visible on the spectra of the mixtures, arising from the solid structure of water ice. In the HQ sample shown in Fig. 3, due to the crystallization processes undergone during the annealing, the IR spectrum shows typical water bands of a cubic phase. In the case of Vap samples, water ices present a low-density amorphous structure, which corresponds to deposition at $100 \mathrm{~K}$, showing broader bands in the IR spectrum.

After generation, all samples were irradiated for 3 to $5 \mathrm{~h}$ by a $1000 \mathrm{~W}$ Xenon Arc lamp. In all cases $\mathrm{NH}_{4}^{+}$and $\mathrm{IO}_{3}^{-}$ IR bands diminish during irradiation process, which is especially evident when 1430 and $745 \mathrm{~cm}^{-1}$ bands are monitored. The dependence on the reduction of these two bands has been analysed in detail. In Fig. 4, we show the plot of $\ln \left(\operatorname{Int}\left(\mathrm{IO}_{3}^{-}\right)_{t} / \operatorname{Int}\left(\mathrm{IO}_{3}^{-}\right)_{0}\right)$ vs. $\ln \left(\operatorname{Int}\left(\mathrm{NH}_{4}^{+}\right)_{t} / \operatorname{Int}\left(\mathrm{NH}_{4}^{+}\right)_{0}\right)$ for the samples. The data of the different linear fittings are collected in Table 2. Note that this correlation is more difficult to examine in the case of $\mathrm{a} \mathrm{O}_{3}^{-} / \mathrm{H}_{2} \mathrm{O}$ ratio higher than 1 , due to (i) the overlap of water and $\mathrm{IO}_{3}^{-}$bands and (ii) the changes that integrated absorption coefficients of $\mathrm{NH}_{4}^{+}$and $\mathrm{IO}_{3}^{-}$infrared bands could undergo in the presence of water, due to the intermolecular hydrogen bond formed in the hydration process. Therefore, when this analysis was carried out for ice mixtures with higher water proportions, it yielded values that could not be adjusted to a line, or the slopes obtained by the best linear fitting were far from typical values, revealing the problems highlighted above. Nevertheless, and taking into account these considerations, the linear fittings present a $R^{2}$ value usually higher than 0.99 . According to Table 2, we can observe that the analysis for samples irradiated at low temperatures (from 100 to $200 \mathrm{~K}$ ) yields similar slopes, showing a mean value of $0.72 \pm 0.05$ or a mean slope value of 0.758 when all the points are included in the linear fitting (see Fig. 4). However, for samples irradiated at temperatures above $200 \mathrm{~K}$ (at 253 or $298 \mathrm{~K}$ ), this analysis yields higher slope values, with a mean slope of $1.01 \pm 0.07$ (or 0.973 when the points for all the experiments are included in the same linear fitting; see Fig. 4), which could be considered in fact as 1 . These different results could be explained by the formation of a volatile $\mathrm{I}_{x} \mathrm{O}_{y}$ product during the photolysis of $\mathrm{IO}_{3}^{-}$, which could be retained in the matrix at temperatures below $200 \mathrm{~K}$. This product typically would show IR absorptions around $740 \mathrm{~cm}^{-1}$ (corresponding to the stretching of the I-O bond; see Maier and Bothur, 1997), and this fact would give a lower rate of diminishing for the $740 \mathrm{~cm}^{-1}$ band intensity with respect to that at $1400 \mathrm{~cm}^{-1}$ (ascribed only to $\mathrm{NH}_{4}^{+}$). At higher temperatures, this product could escape to the gas phase, resulting in a $1: 1$ ratio in the decay of both bands. According to this result, it seems appropriate to assume a $1: 1$ relationship between $\mathrm{NH}_{4}^{+}$loss and $\mathrm{IO}_{3}^{-}$loss in the photolysis of these ices at atmospherically relevant temperatures.

It is important to note that there was no evolution of the IR spectra of the samples observed in dark conditions (this fact was checked many times throughout the experimental measurements).

Typical UV-Vis spectra of common ammonium salts (i.e. $\mathrm{NH}_{4} \mathrm{Cl}$ ) do not display significant absorption bands in the near-UV and visible regions (see Fig. 2), and, to the best of our knowledge, no literature exists on the photolysis of these species. Based on this, the photolysis of ammonium ions is not expected to occur in this spectral range. Therefore, reduction of the IR ammonium bands should be caused by a fast reaction with "reacting" species produced by photolysis 
Table 2. Slopes obtained in the linear regression fit of the representation of the natural logarithm of the integrated intensities (in arbitrary units) of the $\nu_{3}$ of $\mathrm{IO}_{3}^{-}$at different times of irradiation divided by that at $t=0$ vs. the equivalent calculation for the $v_{4}$ band of $\mathrm{NH}_{4}^{+}$for all samples of ammonium iodate at low water proportion (see text for details).

\begin{tabular}{ccc}
\hline$T$ Irrad $(\mathrm{K})$ & Slope & $\mathrm{IO}_{3}^{-} / \mathrm{H}_{2} \mathrm{O}$ ratio \\
\hline 100 & 0.693 & $8: 1$ \\
140 & 0.681 & $1: 1$ \\
150 & 0.769 & $5: 1$ \\
150 & 0.667 & $4: 1$ \\
150 & 0.724 & $5: 1$ \\
180 & 0.785 & $3: 1$ \\
200 & 0.693 & $5: 1$ \\
200 & 0.848 & $8: 1$ \\
200 & 0.750 & $6: 1$ \\
200 & 0.679 & $1: 3$ \\
200 & 0.660 & $3: 1$ \\
200 & 0.753 & $6: 1$ \\
200 & 0.749 & $6: 1$ \\
200 & 0.660 & $8: 1$ \\
200 & 0.822 & $8: 1$ \\
253 & 0.967 & $2: 1$ \\
298 & 1.061 & $15: 1$ \\
\hline
\end{tabular}

of frozen iodate during the irradiation process: HOI, IO and $\mathrm{I}_{2}$ (Spolaor et al., 2013); OIO (Klaning et al., 1981); or other reacting species (e.g. oxygen atoms or anions; see above). It was previously observed that iodine reacts with ammonia in aqueous solution (McAlpine, 1952), and consequently we expected that any of these iodinated compounds obtained in the photolytic process, which could be even more reactive than $\mathrm{I}_{2}$, could themselves react very fast with $\mathrm{NH}_{4}^{+}$.

In addition to those changes at the 1430 and $740 \mathrm{~cm}^{-1}$ bands, other changes are evident in the IR spectra, revealing that not only are ammonium and iodate ions consumed, but also new products are formed (Table S1). These changes are more evident for the low-temperature experiments, around $100 \mathrm{~K}$, since volatile products formed during the photolysis can also be retained on the substrate. Figure 5 shows an example of a pure solid $\mathrm{NH}_{4} \mathrm{IO}_{3}$ salt deposited at $100 \mathrm{~K}$ and irradiated at that temperature. Dotted lines indicate bands that undergo clear changes during photolysis. Stretching $\mathrm{NH}_{4}^{+}$bands (around $3000 \mathrm{~cm}^{-1}$ ) decrease with irradiation, although an increase of water band intensities, more evident in the peak around $3360 \mathrm{~cm}^{-1}$, also occurs, probably due to the residual water background always present in the chamber (note that this effect only occurs at temperatures below $150 \mathrm{~K}$ ). Two new peaks emerge during photolysis, around 2227 and $1300 \mathrm{~cm}^{-1}$. To explain these bands, one possibility could be the formation of $\mathrm{N}_{2} \mathrm{O}$ molecules that present infrared signal around $2200 \mathrm{~cm}^{-1}$. The band around $1300 \mathrm{~cm}^{-1}$ can also be caused by $\mathrm{N}-\mathrm{O}$ stretching vibration,

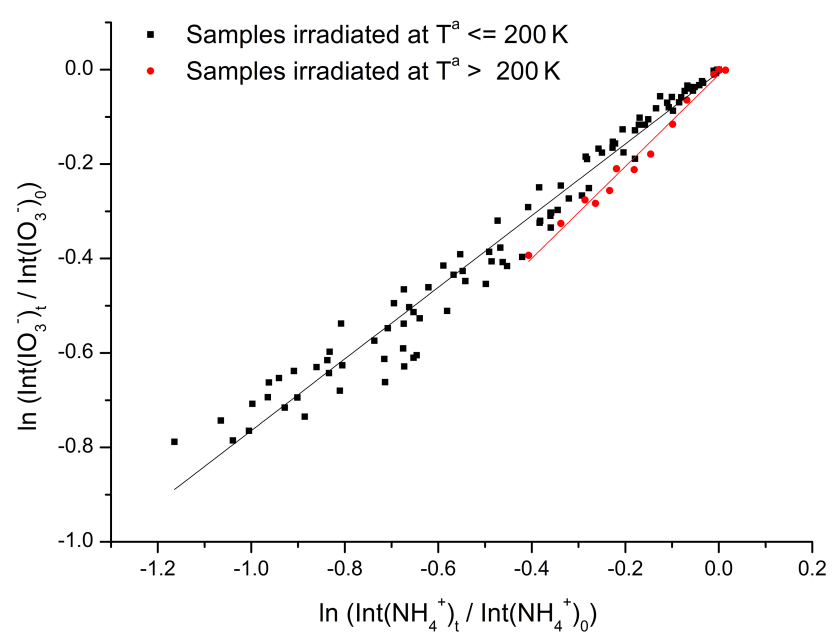

Figure 4. Natural logarithm of the integrated intensities (in arbitrary units) of the $v_{3}$ of $\mathrm{IO}_{3}^{-}$at different times of irradiation divided by that at $t=0$ vs. the equivalent magnitude for the $v_{4}$ band of $\mathrm{NH}_{4}^{+}$ for all samples of ammonium iodate shown in Table 2. Samples irradiated at $T \leq 200 \mathrm{~K}$ and $T>200 \mathrm{~K}$ are shown in black and red, respectively.

which can arise from the reaction of $\mathrm{O}^{*}$ species with ammonium. However, bands around $2227 \mathrm{~cm}^{-1}$ could belong to infrared absorptions of $\mathrm{C}-\mathrm{O}$ stretching modes too. Slight carbon contamination mainly by $\mathrm{CO}_{2}$ molecules is usually found in this type of experiment (Maté et al., 2014). Nevertheless, all these assignments should be considered as speculative.

The mechanism of iodate photolysis is largely unknown. In the study of Spolaor et al. (2013), during the irradiation of $\mathrm{IO}_{3}^{-}$frozen solutions, reactive gaseous iodine species were produced and converted to IOPs for detection. In consequence, we suggest that probably the first step in the photolysis could be the formation of these active species. Mezyk and Elliot (1994) suggested the formation of $\mathrm{IO}_{2}$ in the radiolysis of iodate solutions; this species could also be formed in the photolysis of the ice mixtures, and after being transformed to OIO it reacts itself to form particles. The fact that the rate of decay of $\mathrm{NH}_{4}^{+}$and $\mathrm{IO}_{3}^{-}$follows a $1: 1$ ratio suggests that this active species or one of its co-products reacts very fast with $\mathrm{NH}_{4}^{+}$. In McAlpine's work (McAlpine, 1952), it was proposed that some active species of iodine, like $\mathrm{I}_{2}$ and $\mathrm{HIO}$, can react with ammonia, forming species like $\mathrm{NH}_{2} \mathrm{I}$ and perhaps eventually $\mathrm{NI}_{3}$. Our experiment cannot conclude about the exact mechanism, but it can confirm that $\mathrm{NH}_{4}^{+}$is consumed at the same rate as $\mathrm{IO}_{3}^{-}$.

However, independently of the photolysis mechanism, the photolytic rate constant, $J$ value, for the iodate ion can be calculated according to Eq. (1):

$$
-\frac{\mathrm{d}\left[\mathrm{IO}_{3}^{-}\right]}{\mathrm{d} t}=J\left[\mathrm{IO}_{3}^{-}\right] \text {. }
$$



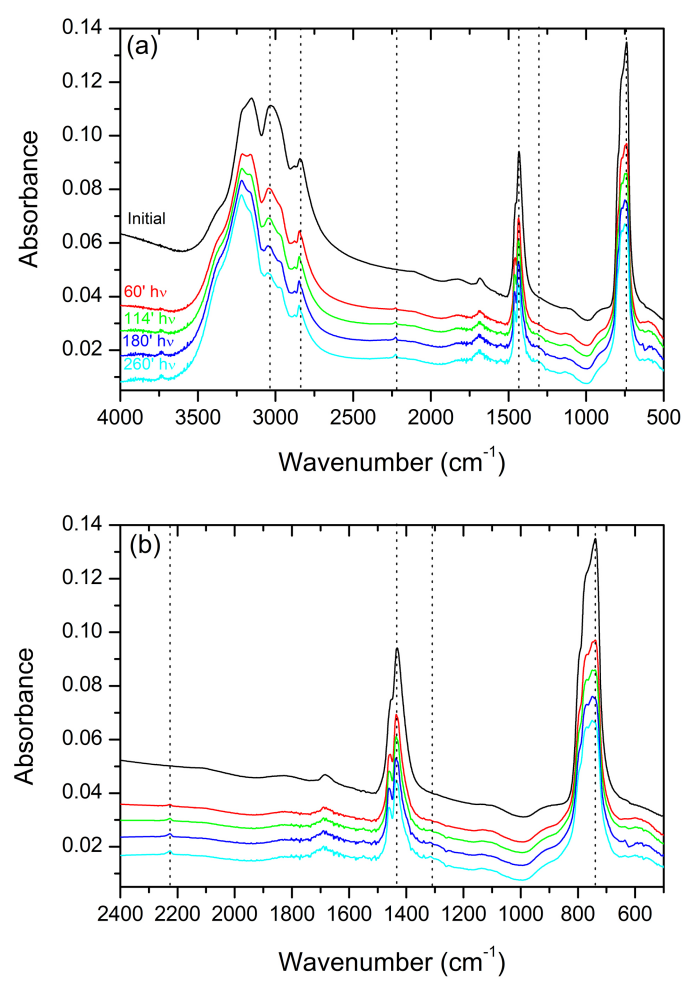

Figure 5. Evolution of the mid-IR transmission spectra of a pure $\mathrm{NH}_{4} \mathrm{IO}_{3}$ deposited at $100 \mathrm{~K}$ during photolysis at that temperature: zero time, 60, 114, 180 and $260 \mathrm{~min}$ of photolysis in black, red, green, dark and light blue, respectively. Panel (a) shows the whole IR spectra between 4000 and $500 \mathrm{~cm}^{-1}$; panel (b) is a zoom-in on the range $2400-600 \mathrm{~cm}^{-1}$. Dotted lines indicate bands that undergo clear changes during the photolysis.

The concentration of the iodate ion can be monitored by integration of the infrared band intensity at ca. $740 \mathrm{~cm}^{-1}$, which, as shown in Fig. 4, could also be equivalent to monitoring the $\mathrm{NH}_{4}^{+}$band at $1430 \mathrm{~cm}^{-1}$ :

$-\frac{\mathrm{d}\left[\mathrm{IO}_{3}^{-}\right]}{\mathrm{d} t}=J\left[\mathrm{IO}_{3}^{-}\right] \ll=\gg-\frac{\mathrm{d}\left[\mathrm{NH}_{4}^{+}\right]}{\mathrm{d} t}=J\left[\mathrm{NH}_{4}^{+}\right]$.

Integrating Eq. (2) and considering that concentration is proportional to IR band intensity,

$\ln \left(I_{t}\right)=\ln \left(I_{0}\right)-J t$,

where $I_{t}$ and $I_{0}$ are the intensity of the band of $\mathrm{NH}_{4}^{+}\left(\right.$or $\mathrm{IO}_{3}^{-}$) at time $t$ and zero, respectively.

According to Eq. (3), a representation of the natural logarithm of the integrated band intensities of $\mathrm{NH}_{4}^{+}$or $\mathrm{IO}_{3}^{-}$signals vs. time of photolysis will give us the $J$ value, as the slope of the line of the best linear fit. This calculation has been done for all deposited samples at different temperatures and water concentrations (Table S1 in the Supplement). Integration limits of the bands differ among the different samples, since the baseline of the spectra is rather sensitive to the generation process and morphologies of the ices mixtures. For this reason, the integration limits of the bands were adjusted for each sample in order to minimize the errors. The calculated mean value for all experiments (at the average light power calculated above) is $J=(4 \pm 2) \times 10^{-5} \mathrm{~s}^{-1}$ (see Supplement for more details). Significant differences in the $J$ values have not been observed among the samples prepared at different conditions, i.e. Vap or HQ deposition of water, different water ice structure (amorphous or cubic), different temperatures of generation and irradiation (from 100 to $298 \mathrm{~K}$ ) or different amount of water in the mixtures. This suggests that the photolysis process does not notably depend on ice morphology, or even on the amorphous or crystalline structure, at least in the range of studied samples.

The photolysis rate can be also estimated according to Eq. (4):

$J=\int_{\lambda_{1}}^{\lambda_{2}} F(\lambda) \sigma(\lambda) \phi(\lambda) \mathrm{d} \lambda$,

where $F(\lambda)$ is the radiative flux, $\sigma(\lambda)$ is the absorption cross section and $\phi(\lambda)$ is the quantum yield of the photolysis reaction. The radiative flux employed in the experiment has been previously calculated (see experimental section), and since visible light is highly reflected by our Si substrate, we have considered a total flux for wavelengths below $400 \mathrm{~nm}$ of $2 \times 0.095 \mathrm{~W} \mathrm{~cm}^{-2}=0.19 \mathrm{~W} \mathrm{~cm}^{-2}$. Please note that the determination of the radiative flux in our experiment is affected by several uncertainties.

In order to estimate the absorption cross section of the ice mixtures, we have recorded the UV-Vis spectra of different concentrations of $\mathrm{NH}_{4} \mathrm{IO}_{3}$ solutions to calculate the molar absorptivity of this salt, which could be also expressed in absorption cross section units (the details are also given in Sect. S5 in the Supplement). Due to the low absorption values beyond $290 \mathrm{~nm}$ in the UV-Vis spectra recorded, it was necessary to extrapolate the calculated cross section values at longer wavelengths (the details are given in the Supplement). Figure 6 depicts the absorption cross section obtained from 200 to $400 \mathrm{~nm}$, which shows a maximum value at $200 \mathrm{~nm}\left(2.52 \times 10^{-17} \mathrm{~cm}^{2}\right.$ molecule $\left.{ }^{-1}\right)$ and a rapid decrease of around 1000 times at $300 \mathrm{~nm}$ (tabulated values are included in Table S3 in the Supplement).

These results are similar to those obtained for other iodate solutions (see UV-Vis spectra in Fig. 2), and, in all cases, nearly null absorptions were recorded above $300 \mathrm{~nm}$, which is also in agreement with those of Saunders et al. (2012) and Awtrey and Connick (1951), who found nearly null absorption above $300 \mathrm{~nm}$ for $\mathrm{NaIO}_{3}$ salt solutions. During the review process of this work, a new study of the absorption of the iodate solutions in the UV-Vis region has appeared in the literature (Kireev and Shnyrev, 2015). In this study, the absorption cross section of $\mathrm{KIO}_{3}$ was measured in the range 


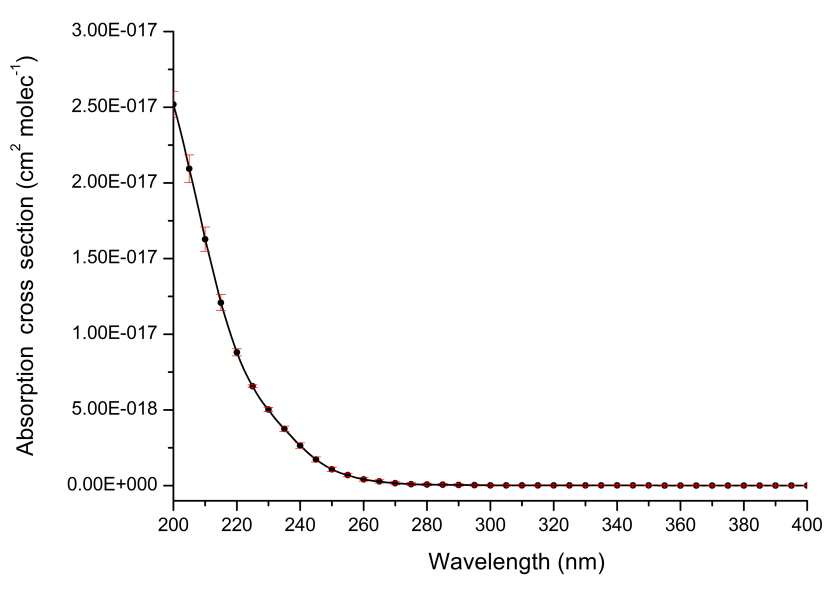

Figure 6. Absorption cross section of the ammonium iodate solution (error bars in red).

from 180 to $245 \mathrm{~nm}$, showing comparable values to those obtained in our study.

However, note that in Fig. 2 the glass window shows nearly null transmission below $250 \mathrm{~nm}$ (where the cross section of iodate peaks). At $300 \mathrm{~nm}$, the absorption cross section is around $2 \times 10^{-20} \mathrm{~cm}^{2}$ molecule ${ }^{-1}$ (although values above $300 \mathrm{~nm}$ should be taken with caution because of the detection limit of the UV-Vis spectrometer; see Sect. S5 in the Supplement), which is, for example, similar to that measured for $\mathrm{CH}_{3} \mathrm{I}$ at this wavelength (Burkholder et al., 2015). However, $\mathrm{CH}_{3} \mathrm{I}$ is rapidly photodissociated in the atmosphere (see Saiz-Lopez et al., 2012), while the photodissociation at solarsimulated irradiation of $\mathrm{IO}_{3}^{-}$solutions has not been observed. Hence, the quantum yield $(\varphi)$ of the process at the tropospherically relevant wavelength should be very different for both systems (for $\mathrm{CH}_{3} \mathrm{I}$, a $\varphi=1$ is assumed).

In order to have a realistic estimation of the wavelength range relevant for iodate photolysis, we have calculated an action spectrum entailing the product of the $\mathrm{IO}_{3}^{-}$absorption cross section and the percent transmittance of the glass window and the lamp output. This spectrum is shown in the Supplement, and it shows null absorption values below $250 \mathrm{~nm}$, which is in fact the blue cut-off of the glass window, registering a maximum around $290 \mathrm{~nm}$ and a continued ca. 1000-fold decrease at $400 \mathrm{~nm}$. At this large wavelength, the cross section of the iodate takes very low values; in fact, this region is out of our detection limit, which is given by the low absorbance values of the salt in this range (see Sect. S5 in the Supplement). Therefore the most likely relevant wavelength interval is assumed to be from 250 to $400 \mathrm{~nm}$.

Nevertheless, we should also consider that these cross section values are obtained for liquid solutions, so they could be somehow different from frozen samples as in our case. Several studies have shown that the absorbance spectrum of a species in ice could be estimated by red-shifting the solution spectrum (e.g. Dubowski and Hoffmann, 2000). More-
Table 3. Quantum yield estimation for the photolysis process studied as variation of the red shift of the cross section (from 250 to $400 \mathrm{~nm}$ ) obtained for the ammonium iodate solution.

\begin{tabular}{rrrr}
\hline $\begin{array}{r}\mathrm{nm} \\
\text { red-shifted }\end{array}$ & $\begin{array}{r}\text { Integrated } \\
\text { cross } \\
\text { section }\end{array}$ & $\begin{array}{r}\text { Quantum } \\
\text { yield }\end{array}$ & $\begin{array}{r}\text { Integrated } \\
\text { (cross section } \\
\times \mathrm{q} . \text { yield) }\end{array}$ \\
\hline 0 & $1.224 \times 10^{-17}$ & 0.0200 & $2.443 \times 10^{-19}$ \\
10 & $3.018 \times 10^{-17}$ & 0.00866 & $2.615 \times 10^{-19}$ \\
20 & $6.814 \times 10^{-17}$ & 0.00368 & $2.507 \times 10^{-19}$ \\
30 & $1.356 \times 10^{-16}$ & 0.00164 & $2.227 \times 10^{-19}$ \\
40 & $2.587 \times 10^{-16}$ & 0.000783 & $2.024 \times 10^{-19}$ \\
50 & $4.671 \times 10^{-16}$ & 0.000391 & $1.825 \times 10^{-19}$ \\
\hline
\end{tabular}

over, simulations with methyl peroxide in frozen water predict that absorption spectra are also red-shifted at low temperatures (Epstein et al., 2012). According to these previous studies, we evaluate the red shift of the liquid cross section values of $\mathrm{NH}_{4} \mathrm{IO}_{3}$ to obtain a more realistic value of the absorption cross section of the iodate ice mixtures, as well as the implications for the estimated photolysis quantum yield (Eq. 4). Since there is no information of the quantum yield wavelength, a constant quantum yield is assumed for the entire wavelength range. The results are summarized in Table 3. The integrated value of the cross section from 250 to $400 \mathrm{~nm}$ peaks for a red shift of $50 \mathrm{~nm}$, while at this red shift we obtain the lowest quantum yield value (ca. 0.0004). The opposite is obtained when the cross section values are not red-shifted. The maximum value of the product of these two magnitudes is obtained for a red shift of $10 \mathrm{~nm}\left(2.61 \times 10^{-19} \mathrm{~cm}^{2} \mathrm{~nm}\right)$. This value can then be considered as the integrated cross section of the photolysis process. For comparison purposes, the integrated cross section of the photolysis of $\mathrm{CH}_{3} \mathrm{I}$ (considering a yield of $\varphi=1$ ) in the interval from 250 to $365 \mathrm{~nm}$ is $2.88 \times 10^{-17} \mathrm{~cm}^{2} \mathrm{~nm}$ (Burkholder et al., 2015), which is around 100 times larger. However, our integrated value is close to that of the integrated cross section of $\mathrm{O}_{3}$ in the spectral interval 410-690 nm (Chappuis band), which is ca. $6.6 \times 10^{-20} \mathrm{~cm}^{2} \mathrm{~nm}$ (Bogumil et al., 2001).

According to these results, the photoreactivity of the iodate salts should be related to the low-temperature effect and to the fact that iodate solutions or salts are frozen, in agreement with the results from Spolaor et al. (2013). It is well known that different photochemical reactions are greatly accelerated in frozen solution due to the concentration effect of solutes in porous cavities or channels formed in the water ice network (see e.g. Grannas et al., 2007; Kahan et al., 2010, and references therein). For the case of $\mathrm{NO}_{3}^{-}$, it has been recently shown that the photolysis in frozen ices is considerably higher than in solutions (Marcotte et al., 2015), which is similar to our observations for iodate salts.

The increase of photolysis rates at low temperature can be caused by either a substantial change in the absorption cross 
section (due to a red shift in relation to solution) or an increase of the quantum yield of the process, or in fact by both factors at the same time. Our experiments do not allow discrimination of these factors which need to be further studied in subsequent experimental work. Instead, the integrated absorption cross section obtained in this work should be regarded as a lower limit. The reason is mainly the limitations associated with distributing the samples homogeneously during deposition, which could generate areas free of samples on the substrate. For these cases, the irradiance received by the samples could be lower than calculated (which assumes a homogeneous distribution of the sample), thereby leading to a higher calculated absorption cross section value than the one obtained in this work. Based on the dispersion of our results, we have estimated that this effect could account for an increase in this value by up to a factor of 2 .

In addition, due to the characteristics of our experimental setup, our results represent the photolysis of the iodate in the bulk. However, as in the case of $\mathrm{NO}_{3}^{-}$, this process could be much faster on the surface (Marcotte et al., 2015). In conclusion, further experiments should be conducted to confirm the values of the absorption cross section and quantum yield, and to evaluate the influence of the ice-air interface in the process of frozen iodate salt photolysis.

\subsection{Atmospheric implications}

We have incorporated the experimentally derived absorption cross section value into an atmospheric model in order to assess the implications that this process could have in polar atmospheric chemistry. Although high levels of reactive iodine have been measured in coastal Antarctica, the emission mechanism over ice still remains unclear. We use an atmospheric model (for details see Saiz-Lopez et al., 2008) of the Antarctic boundary layer to assess the potential of iodate photolysis to release reactive iodine to the polar atmosphere. The model is initialized with typical concentrations of atmospheric constituents in coastal Antarctica (Jones et al., 2008) for October. An action spectrum considering the Antarctic photon flux has also been calculated (see Sect. S5 in the Supplement), which shows approximately 6-times-lower intensity than that for the laboratory experiments. The reason for such a difference is the smaller Antarctic sunlight photon flux. We constrain the ice surface in the model with an average iodate concentration at the ice surface of $19 \mathrm{nM}$, as recently measured over the Weddell Sea (Atkinson et al., 2012). The model incorporates a two-stream radiation code to compute the actinic flux at the surface for springtime Antarctic irradiation conditions (Saiz-Lopez et al., 2008), and the iodate absorption cross sections and quantum yield values estimated in this work. We assume that there is an iodine atom unity conversion of iodate into reactive gas phase following iodate photolysis. This assumption is based on previous studies on the photolysis of nitrite and nitrate on ice, which pointed out that $1: 1$ nitrogen atom conversion from inert to reacting species was necessary to model the $\mathrm{NO}_{x}$ concentrations in the Antarctic atmosphere (Boxe and SaizLopez, 2008). The model sensitivities of the photoreduction of iodate in ice for the different estimated values of absorption cross sections and quantum yields provide a range of atmospheric IO levels between 0.2 and $1.0 \mathrm{pptv}$. These levels of IO are lower than the highest values measured in the biologically active Weddell Sea region. However, lower IO concentrations have also been reported in other coastal regions away from the Weddell Sea (Schönhardt et al., 2008). We would like to highlight that the IO concentration range given by the model is proportional to the integrated cross section values of the photolytic process (product of the cross section and quantum yield in the selected wavelength interval) used for iodate, and therefore larger absorption cross sections would result in larger modelled IO levels. The photolysis of iodate could then provide a source of iodine that accounts for some of the comparatively low levels observed and, to a lesser extent, also contribute to the iodine emissions over the Weddell Sea zone. Note that the model does not consider the potential loss at the ice surface of the iodine photofragments resulting from the iodate photolysis. The model results suggest, within the uncertainties highlighted above, that the photolysis of iodate on the surface of ice can potentially constitute an abiotic pathway for the release of active iodine to the polar atmosphere. Further laboratory work and fieldwork are needed to better assess the environmental implications of the photolysis of iodate on ice surfaces.

\section{Summary and conclusions}

We have explored the photolysis of ammonium iodate salt in frozen solutions. The samples were generated by different deposition methods, and at different temperatures and water concentrations, in order to obtain samples of different morphologies. The samples were processed by simulated solar light with an average light power of $0.19 \mathrm{~W} \mathrm{~cm}^{-2}$ over the wavelength range of 250 to $400 \mathrm{~nm}$. In the different experiments, the similar evolution of the IR spectra confirms the photolysis of iodate salts. The photolysis rates obtained are similar for all samples, within our experimental uncertainties, indicating that in the photolytic process there is a limited influence of the morphology and structure of the water ice matrix. The bands of $\mathrm{NH}_{4}^{+}$and $\mathrm{IO}_{3}^{-}$decrease during irradiation, and new small bands appear. As a result of these experiments, the absorption cross section of iodate in an ammonium frozen salt and the quantum yield are estimated for the first time at wavelengths relevant for tropospheric studies $\left(\sigma=1.22 \times 10^{-17} \mathrm{~cm}^{2} \mathrm{~nm}\right.$ and $\varphi=0.02$ from 250 to $400 \mathrm{~nm})$. However, due to the experimental limitations, this value has to be considered mainly as a lower limit, and further experiments are needed to confirm it. These new data have been included in an atmospheric model of the Antarctic boundary layer to assess its potential environmental rel- 
evance. The model predicts, within uncertainties, that the photolysis of iodate in ice could yield atmospheric IO levels ranging $0.2-1.0 \mathrm{pptv}$, which could be higher if we consider a larger absorption cross sections for the photolysis of iodate. According to this, we suggest that the photolysis of iodate on the surface of ice can potentially constitute a pathway for the release of active iodine to the polar atmosphere.

\section{The Supplement related to this article is available online at doi:10.5194/acp-16-12703-2016-supplement.}

Acknowledgements. Óscar Gálvez acknowledges financial support from the Ministerio de Ciencia e Innovación, "Ramón y Cajal" programme, and from the Ministerio de Economía y Competitividad, project "CGL2013-48415-C2-1-R". M. Teresa Baeza-Romero and Mikel Sanz acknowledge financial support from the Ministerio de Economía y Competitividad, project "CGL2013-48415-C2-2". Óscar Gálvez, M. Teresa Baeza-Romero and Mikel Sanz acknowledge financial support from the Spanish crowdfunding platform PRECIPITA from the FECYT foundation. Authors acknowledge the different reviewers (specially the helpful comments of referee no. 4) of this manuscript, who have contributed to noticeably improving this article.

Edited by: M. Ammann

Reviewed by: four anonymous referees

\section{References}

Abad, L., Bermejo, D., Herrero, V. J., Santos, J., and Tanarro, I.: Performance of a solenoid driven pulsed molecular beam source, Rev. Sci. Instrum., 66, 3826-3832, doi:10.1063/1.1145444, 1995.

Allan, J. D., Williams, P. I., Najera, J., Whitehead, J. D., Flynn, M. J., Taylor, J. W., Liu, D., Darbyshire, E., Carpenter, L. J., Chance, R., Andrews, S. J., Hackenberg, S. C., and McFiggans, G.: Iodine observed in new particle formation events in the Arctic atmosphere during ACCACIA, Atmos. Chem. Phys., 15, 55995609, doi:10.5194/acp-15-5599-2015, 2015.

Assmy, P., Ehn, J. K., Fernández-Méndez, M., Hop, H., Katlein, C., Sundfjord, A., Bluhm, K., Daase, M., Engel, A., Fransson, A., Granskog, M. A., Hudson, S. R., Kristiansen, S., Nicolaus, M., Peeken, I., Renner, A. H. H., Spreen, G., Tatarek, A., and Wiktor, J.: Floating Ice-Algal Aggregates below Melting Arctic Sea Ice, PLoS ONE, 8, e76599, doi:10.1371/journal.pone.0076599, 2013.

Atkinson, H. M., Huang, R.-J., Chance, R., Roscoe, H. K., Hughes, C., Davison, B., Schönhardt, A., Mahajan, A. S., Saiz-Lopez, A., Hoffmann, T., and Liss, P. S.: Iodine emissions from the sea ice of the Weddell Sea, Atmos. Chem. Phys., 12, 11229-11244, doi:10.5194/acp-12-11229-2012, 2012.

Awtrey, A. D. and Connick, R. E.: The Absorption Spectra of $\mathrm{I}_{2}$, $\mathrm{I}_{3}^{-}, \mathrm{I}^{-}, \mathrm{IO}_{3}^{-}, \mathrm{S}_{4} \mathrm{O}_{6}^{=}$and $\mathrm{S}_{2} \mathrm{O}_{3}^{=}$. Heat of the Reaction $\mathrm{I}_{3}^{-}=\mathrm{I}_{2}+\mathrm{I}$, J. Am. Chem. Soc., 73, 1842-1843, doi:10.1021/ja01148a504, 1951.
Baker, A. R.: Inorganic iodine speciation in tropical Atlantic aerosol, Geophys. Res. Lett., 31, L23S02, doi:10.1029/2004g1020144, 2004.

Baker, A. R., Thompson, D., Campos, M. L. A. M., Parry, S. J., and Jickells, T. D.: Iodine concentration and availability in atmospheric aerosol, Atmos. Environ., 34, 4331-4336, doi:10.1016/S1352-2310(00)00208-9, 2000.

Bogumil, K., Orphal, J., Burrows, J. P., and Flaud, J. M.: Vibrational progressions in the visible and near-ultraviolet absorption spectrum of ozone, Chem. Phys. Lett., 349, 241-248, doi:10.1016/S0009-2614(01)01191-5, 2001.

Boxe, C. S. and Saiz-Lopez, A.: Multiphase modeling of nitrate photochemistry in the quasi-liquid layer (QLL): implications for $\mathrm{NO}_{x}$ release from the Arctic and coastal Antarctic snowpack, Atmos. Chem. Phys., 8, 4855-4864, doi:10.5194/acp-8-4855-2008, 2008.

Burkholder, J. B., Sander, S. P., Abbatt, J., Barker, J. R., Huie, R. E., Kolb, C. E., Kurylo, M. J., Orkin, V. L., Wilmouth, D. M., and Wine, P. H.: Chemical Kinetics and Photochemical Data for Use in Atmospheric Studies, Evaluation No. 18, JPL Publication 15-10, Jet Propulsion Laboratory, Pasadena, available at: http: //jpldataeval.jpl.nasa.gov (last access: 7 October 2016), 2015.

Calvert, J. G. and Lindberg, S. E.: The potential influence of iodinecontaining compounds on the chemistry of the troposphere in the polar spring. II. Mercury depletion, Atmos. Environ., 38, 51055116, doi:10.1016/j.atmosenv.2004.05.050, 2004.

Dubowski, Y. and Hoffmann, M. R.: Photochemical transformations in ice: Implications for the fate of chemical species, Geophys. Res. Lett., 27, 3321-3324, doi:10.1029/2000g1011701, 2000.

Epstein, S. A., Shemesh, D., Tran, V. T., Nizkorodov, S. A., and Gerber, R. B.: Absorption Spectra and Photolysis of Methyl Peroxide in Liquid and Frozen Water, J. Phys. Chem. A, 116, 6068-6077, doi:10.1021/jp211304v, 2012.

Frieß, U., Wagner, T., Pundt, I., Pfeilsticker, K., and Platt, U.: Spectroscopic measurements of tropospheric iodine oxide at Neumayer Station, Antarctica, Geophys. Res. Lett., 28, 1941-1944, doi:10.1029/2000gl012784, 2001.

Gálvez, Ó., Maté, B., Martín-Llorente, B., Herrero, V. J., and Escribano, R.: Phases of Solid Methanol, J. Phys. Chem. A, 113, 3321-3329, doi:10.1021/jp810239r, 2009.

Gálvez, O., Maté, B., Herrero, V. J., and Escribano, R.: Ammonium and Formate Ions in Interstellar Ice Analogs, Astrophys. J., 724, 539-545, doi:10.1088/0004-637X/724/1/539, 2010.

Gilfedder, B. S., Lai, S. C., Petri, M., Biester, H., and Hoffmann, T.: Iodine speciation in rain, snow and aerosols, Atmos. Chem. Phys., 8, 6069-6084, doi:10.5194/acp-8-6069-2008, 2008.

Grannas, A. M., Jones, A. E., Dibb, J., Ammann, M., Anastasio, C., Beine, H. J., Bergin, M., Bottenheim, J., Boxe, C. S., Carver, G., Chen, G., Crawford, J. H., Dominé, F., Frey, M. M., Guzmán, M. I., Heard, D. E., Helmig, D., Hoffmann, M. R., Honrath, R. E., Huey, L. G., Hutterli, M., Jacobi, H. W., Klán, P., Lefer, B., McConnell, J., Plane, J., Sander, R., Savarino, J., Shepson, P. B., Simpson, W. R., Sodeau, J. R., von Glasow, R., Weller, R., Wolff, E. W., and Zhu, T.: An overview of snow photochemistry: evidence, mechanisms and impacts, Atmos. Chem. Phys., 7, 43294373, doi:10.5194/acp-7-4329-2007, 2007.

Jones, A. E., Wolff, E. W., Salmon, R. A., Bauguitte, S. J.-B., Roscoe, H. K., Anderson, P. S., Ames, D., Clemitshaw, K. C., Fleming, Z. L., Bloss, W. J., Heard, D. E., Lee, J. D., Read, 
K. A., Hamer, P., Shallcross, D. E., Jackson, A. V., Walker, S. L., Lewis, A. C., Mills, G. P., Plane, J. M. C., Saiz-Lopez, A., Sturges, W. T., and Worton, D. R.: Chemistry of the Antarctic Boundary Layer and the Interface with Snow: an overview of the CHABLIS campaign, Atmos. Chem. Phys., 8, 3789-3803, doi:10.5194/acp-8-3789-2008, 2008.

Kahan, T. F., Kwamena, N.-O. A., and Donaldson, D. J.: Different photolysis kinetics at the surface of frozen freshwater vs. frozen salt solutions, Atmos. Chem. Phys., 10, 10917-10922, doi:10.5194/acp-10-10917-2010, 2010.

Kim, K., Yabushita, A., Okumura, M., Saiz-Lopez, A., Cuevas, C. A., Blaszczak-Boxe, C. S., Min, D. W., Yoon, H.-I., and Choi, W.: Production of molecular iodine and triiodide in the frozen solution of iodide: implication for polar atmosphere, Environ. Sci. Technol., 50, 1280-1287, doi:10.1021/acs.est.5b05148, 2016.

Kireev, S. V. and Shnyrev, S. L.: Study of molecular iodine, iodate ions, iodide ions, and triiodide ions solutions absorption in the, Laser Physics, 25, 075602, doi:10.1088/1054660X/25/7/075602, 2015

Klaning, U. K., Sehested, K., and Wolff, T.: Laser flash photolysis and pulse radiolysis of iodate and periodate in aqueous solution. Properties of iodine(VI), J. Chem. Soc. Farad. T. 1, 77, 17071718, doi:10.1039/f19817701707, 1981.

Laniewski, K., Borén, H., and Grimvall, A.: Fractionation of halogenated organic matter present in rain and snow, Chemosphere, 38, 393-409, doi:10.1016/S0045-6535(98)00181-7, 1999.

Maier, G. and Bothur, A.: Matrix-Isolation of Iodine Superoxide and Iodine Dioxide, Chem. Ber., 130, 179-181, doi:10.1002/cber.19971300207, 1997.

Marcotte, G., Marchand, P., Pronovost, S., Ayotte, P., Laffon, C., and Parent, P.: Surface-Enhanced Nitrate Photolysis on Ice, J. Phys. Chem. A, 119, 1996-2005, doi:10.1021/jp511173w, 2015.

Mastrapa, R. M., Sandford, R. M., Roush, T. L., Cruikshank, D. P., and Dalle Ore, C. M.: Optical Constants of Amorphous and Crystalline $\mathrm{H}_{2} \mathrm{O}$-ice: $2.5-22 \mu \mathrm{m}\left(4000-455 \mathrm{~cm}^{-1}\right)$ Optical Constants of $\mathrm{H}_{2} \mathrm{O}$-ice, Astrophys. J., 701, 1347-1356, doi:10.1088/0004637X/701/2/1347, 2009.

Maté, B., Gálvez, O., Herrero, V. J., Fernández-Torre, D., Moreno, M. A., and Escribano, R.: Water-Ammonium ICES and the Elusive $6.85 \mu \mathrm{m}$ Band, Astrophys. J. Lett., 703, L178-L182, doi:10.1088/0004-637X/703/2/L178, 2009.

Maté, B., Rodriguez-Lazcano, Y., and Herrero, V. J.: Morphology and crystallization kinetics of compact (HGW) and porous (ASW) amorphous water ice, Phys. Chem. Chem. Phys., 14, 10595-10602, doi:10.1039/c2cp41597f, 2012.

Maté, B., Tanarro, I., Moreno, M. A., Jimenez-Redondo, M., Escribano, R., and Herrero, V. J.: Stability of carbonaceous dust analogues and glycine under UV irradiation and electron bombardment, Faraday Discuss., 168, 267-285, doi:10.1039/c3fd00132f, 2014.

Mayer, E.: New method for vitrifying water and other liquids by rapid cooling of their aerosols, J. Appl. Phys., 58, 663-667, doi:10.1063/1.336179, 1985.

McAlpine, R. K.: The Reaction of Dilute Iodine and Ammonia Solutions, J. Am. Chem. Soc., 74, 725-727, doi:10.1021/ja01123a041, 1952.

Mezyk, S. P. and Elliot, A. J.: Pulse radiolysis of lodate in aqueous solution, J. Chem. Soc. Faraday T., 90, 831-836, doi:10.1039/ft9949000831, 1994.
Ocampo, J. and Klinger, J.: Adsorption of $\mathrm{N}_{2}$ and $\mathrm{CO}_{2}$ on ice, J. Colloid Interf. Sci., 86, 377-383, doi:10.1016/00219797(82)90083-2, 1982.

Pechtl, S., Lovejoy, E. R., Burkholder, J. B., and von Glasow, R.: Modeling the possible role of iodine oxides in atmospheric new particle formation, Atmos. Chem. Phys., 6, 505-523, doi:10.5194/acp-6-505-2006, 2006.

Read, K. A., Mahajan, A. S., Carpenter, L. J., Evans, M. J., Faria, B. V. E., Heard, D. E., Hopkins, J. R., Lee, J. D., Moller, S. J., Lewis, A. C., Mendes, L., McQuaid, J. B., Oetjen, H., Saiz-Lopez, A., Pilling, M. J., and Plane, J. M. C.: Extensive halogen-mediated ozone destruction over the tropical Atlantic Ocean, Nature, 453, 1232-1235, 2008.

Roscoe, H. K., Jones, A. E., Brough, N., Weller, R., Saiz-Lopez, A., Mahajan, A. S., Schoenhardt, A., Burrows, J. P., and Fleming, Z. L.: Particles and iodine compounds in coastal Antarctica, J. Geophys. Res.-Atmos., 120, 7144-7156, doi:10.1002/2015jd023301, 2015.

Saiz-Lopez, A., Chance, K., Liu, X., Kurosu, T. P., and Sander, S. P.: First observations of iodine oxide from space, Geophys. Res. Lett., 34, L12812, doi:10.1029/2007g1030111, 2007a.

Saiz-Lopez, A., Mahajan, A. S., Salmon, R. A., Bauguitte, S. J.B., Jones, A. E., Roscoe, H. K., and Plane, J. M. C.: Boundary Layer Halogens in Coastal Antarctica, Science, 317, 348-351, doi:10.1126/science.1141408, 2007b.

Saiz-Lopez, A., Plane, J. M. C., Mahajan, A. S., Anderson, P. S., Bauguitte, S. J.-B., Jones, A. E., Roscoe, H. K., Salmon, R. A., Bloss, W. J., Lee, J. D., and Heard, D. E.: On the vertical distribution of boundary layer halogens over coastal Antarctica: implications for $\mathrm{O}_{3}, \mathrm{HO}_{x}, \mathrm{NO}_{x}$ and the $\mathrm{Hg}$ lifetime, Atmos. Chem. Phys., 8, 887-900, doi:10.5194/acp-8-887-2008, 2008.

Saiz-Lopez, A., Plane, J. M. C., Baker, A. R., Carpenter, L. J., von Glasow, R., Gómez Martín, J. C., McFiggans, G., and Saunders, R. W.: Atmospheric Chemistry of Iodine, Chem. Rev., 112, 1773-1804, doi:10.1021/cr200029u, 2012.

Saiz-Lopez, A., Blaszczak-Boxe, C. S., and Carpenter, L. J.: A mechanism for biologically induced iodine emissions from sea ice, Atmos. Chem. Phys., 15, 9731-9746, doi:10.5194/acp-159731-2015, 2015.

Saunders, R. W., Kumar, R., MacDonald, S. M., and Plane, J. M. C.: Insights into the Photochemical Transformation of Iodine in Aqueous Systems: Humic Acid Photosensitized Reduction of Iodate, Environ. Sci. Technol., 46, 11854-11861, doi:10.1021/es3030935, 2012.

Schönhardt, A., Richter, A., Wittrock, F., Kirk, H., Oetjen, H., Roscoe, H. K., and Burrows, J. P.: Observations of iodine monoxide columns from satellite, Atmos. Chem. Phys., 8, 637-653, doi:10.5194/acp-8-637-2008, 2008.

Schutte, W. A. and Khanna, R. K.: Origin of the 6.85 micron band near young stellar objects: The ammonium ion $\left(\mathrm{NH}_{4}^{+}\right)$revisited, Astron. Astrophys., 398, 1049-1062, 2003.

Spolaor, A., Vallelonga, P., Plane, J. M. C., Kehrwald, N., Gabrieli, J., Varin, C., Turetta, C., Cozzi, G., Kumar, R., Boutron, C., and Barbante, C.: Halogen species record Antarctic sea ice extent over glacial-interglacial periods, Atmos. Chem. Phys., 13, 66236635, doi:10.5194/acp-13-6623-2013, 2013. 